\title{
A gravity waves study close to the Andes mountains in Patagonia and Antarctica with GPS radio occultation observations
}

\author{
P. Alexander, D. Luna, P. Llamedo, and A. de la Torre \\ Departamento de Física, Facultad de Ciencias Exactas y Naturales, Universidad de Buenos Aires, Buenos Aires, Argentina
}

Received: 20 August 2009 - Revised: 22 December 2009 - Accepted: 16 February 2010 - Published: 19 February 2010

\begin{abstract}
We first study the seasonal and geographical behavior of gravity wave activity in the lower stratosphere over the southernmost Andes mountains and their prolongation in the Antarctic Peninsula by global positioning system (GPS) radio occultation (RO) temperature profiles, obtained between years 2002 and 2005 by the CHAllenging Minisatellite Payload (CHAMP) mission. The observed features complement observations in the same zone by other satellite passive remote sensing instruments, which are able to detect different height regions and other spectral intervals of the wave spectrum. Comparisons with previous GPS RO studies in smaller areas than the one covered in our analysis are also established. Significant seasonal variation of wave activity is observed in our work, in agreement with results from other instruments. The locations of significant cases indicate that topography is an important source. Some strong wave activity is also found over open ocean. Critical level filtering is shown to have an attenuation effect, implying that a large fraction of the observed activity can be considered to be an outcome of mountain waves. The studied region has a significant advantage as compared to other regions of our planet: it generates wavefronts nearly aligned with the North-South direction (almost parallel to the mountains), whereby this geometry favors the wave detection by the nearly meridional line of sight characterizing most of the GPS RO observations used. A distribution of the observed gravity waves in terms of amplitudes and wavelengths is also presented.
\end{abstract}

Keywords. Meteorology and atmospheric dynamics (Middle atmosphere dynamics; Waves and tides)

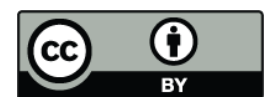

Correspondence to: P. Alexander (peter@df.uba.ar)

\section{Introduction}

Gravity wave (GW) drag in general circulation models has been usually treated with parameterizations. A primary limitation of the development and validation of these representations has been the lack of observational constraints on waves. Moreover, it is very difficult to obtain a complete view of three-dimensional time-varying atmospheric processes with a single instrument or technique. Radiosonde, lidar, radar, and rocket measurements generally provide local observations of GW, whereas measurements on board satellites can yield global coverage (e.g., Wu and Waters, 1996; Tsuda et al., 2000). Studies in unexplored areas specially benefit from the last platform. However, many of the observed wave properties are related to the instrumental sensitivities to certain portions of the wave spectrum or to the operational heights (e.g., Kuo et al., 2005; Wu et al., 2006). In addition, background winds affect the vertical wavelengths (e.g., Alexander, 1998) and may move waves in or out of the filtering window of each observational technique. Source variability and critical level filtering are also important factors in the observed wave activity variability. The outcome of passive remote sensing satellite observations is also strongly dependent on the relative orientation of the line of sight (LOS) and the wavefronts to be detected (e.g., Preusse et al., 2002; Lange and Jacobi, 2003; Jiang et al., 2004; Alexander et al., 2008).

Due to their similar measurement characteristics, all satellite limb viewing techniques have a good vertical resolution and a coarse horizontal resolution (typically $1 \mathrm{~km}$ against $100 \mathrm{~km}$ ). These methods are sensitive to overlapping or neighboring areas of the wavelength spectrum. Operational in another region of wavelength space, nadir viewing techniques have better horizontal and worse vertical resolution. Temperature profiles from different space-borne sounders may provide complementary views. The nadir viewing Advanced Microwave Sounding Unit-A (AMSUA) radiances are sensitive to temperature perturbations of

Published by Copernicus Publications on behalf of the European Geosciences Union. 
horizontal wavelengths between 100 and $200 \mathrm{~km}$ and vertical wavelengths greater than $5 \mathrm{~km}$. The Atmospheric Infrared Sounder (AIRS) nadir instrument has a different horizontal and vertical resolution range, respectively around between 20 and $60 \mathrm{~km}$ and greater than $15 \mathrm{~km}$. Both of the above nadir instruments have been used to study the lower stratosphere. Upper Atmosphere Research Satellite Microwave Limb Sounder (UARS MLS) limb radiances are able to yield temperature fluctuations with vertical wavelengths greater than $10 \mathrm{~km}$ and horizontal wavelengths between 30 and $100 \mathrm{~km}$ and provide data in the $28-80 \mathrm{~km}$ altitude range. Stratospheric temperature measurements from infrared limb sounding like those obtained from the Cryogenic Infrared Spectrometers and Telescopes for the Atmosphere (CRISTA) and global positioning system (GPS) radio occultation (RO) have a horizontal resolution of around $100 \mathrm{~km}$, whereas the vertical resolutions are respectively around 4 and $1 \mathrm{~km}$. The GPS RO technique is capable of retrieving temperature profiles of the troposphere and lower stratosphere with sub-Kelvin accuracy and long-term stability, regardless of weather conditions. It has the best global coverage over the last years against all the other techniques. Previous regional studies with these data only covered parts of the region of interest in this study.

Last decade studies that rely on remote sensing techniques on board of satellites have shown that there is an extratropical zone in the Southern Hemisphere, close to the Patagonian Andes, their prolongation in the Antarctic Peninsula and towards the South Atlantic Ocean, that exhibits a strong wave activity in the upper troposphere and lower stratosphere in winter and spring (see references below). A similar feature has been found during winter in the North Atlantic region at roughly equivalent latitudes with UARS MLS and AMSU-A data (McLandress et al., 2000; Wu and Zhang, 2004). The southern observations provide strong indications that mountain waves forced by flow over the Andes may routinely reach the stratosphere. Wu and Waters $(1996,1997)$ used UARS MLS data between June and July 1993 and found enhanced wave activity to the East of the southernmost Andes, the Antarctica Peninsula and over the open ocean. Eckermann and Preusse (1999) and Preusse et al. (2002) showed large amplitude temperature oscillations at respectively 40 $50 \mathrm{~S}$ and $40-57 \mathrm{~S}$ over the southernmost Andes in soundings from CRISTA on November 1994. Enhanced activity in the data extended further to the lee side and toward the ocean. Analysis of UARS MLS data by McLandress et al. (2000) over the southern Andes and the Antarctic Peninsula between June and August 1992-1997 also showed enhanced temperature fluctuations. A global study of GPS RO data by Tsuda et al. (2000) exhibited a significant wave activity over the southern Andes. Jiang et al. (2002b) found in a global UARS MLS data study a strong wave activity close to the southern Andes and the Antarctic Peninsula between $35 \mathrm{~S}$ and $75 \mathrm{~S}$ during the winters of 1992-1997. The influence extended in a long tail toward the east over the ocean. Jiang et al. (2002a) used UARS MLS observations and found over the southernmost continental Andes (30-50 S, 85-55 W) and the Drake Passage a significant wave activity between May and September 1995-1996. They stated that Eckermann and Preusse (1999) and Preusse et al. (2002) observed an uncommon large late-spring stratospheric mountain wave due to fortuitous conditions, as usually November-April is low season. Wu and Jiang (2002) used UARS MLS 1992-1994 data over Antarctica and the surroundings to study wave activity. A strong enhancement of wave energy over the Drake Passage (70-45 W, 50-70 S) was shown to peak in August and September, possibly associated with the topography close to both continental tips. Hocke et al. (2002) used GPS RO data from the GPS/MET satellite mission to show in a southern mid-latitude study that during October 1995 GW fluctuations had a strong and sharp maximum over the Andes between 40-55 S. Significant GW activity at $25 \mathrm{~km}$ height above the southern tip of South America and the Antarctic Peninsula was also found with CRISTA data from August 1997 (Ern et al., 2004). Further North, the presence of significant lower stratosphere wave activity over the Andes between $30 \mathrm{~S}$ and $40 \mathrm{~S}$, mainly during late winter and early spring, has been outlined in studies of de la Torre and Alexander (2005) and de la Torre et al. (2006b). Wu (2004) used AMSU-A measurements and observed enhancements over the southern Andes and the Antarctic Peninsula during June-August 2003 in a southern mid- and high-latitude study. Alexander and Barnet (2007) employed data from AIRS on September 2003, mainly over 36-56 S and 76-56 W, to show some significant wave events over the Andes, the Antarctic Peninsula and the open ocean. Alexander and Teitelbaum (2007) studied a single large amplitude mountain wave over the Antarctic Peninsula with AIRS data from September 2003. Baumgaertner and McDonald (2007) detected with GPS RO data from January 2002 to June 2006 a maximum of activity between August and November from the tropopause to a height of $35 \mathrm{~km}$ over Antarctica, mainly over the Peninsula.

This study employed temperature profiles obtained by the CHAllenging Minisatellite Payload (CHAMP) mission (e.g., Schmidt et al., 2004; Wickert et al., 2005) over the years 2002-2005. According to the morphology of the mountains in the studied region, the nearly-meridional LOS of most of its retrievals optimizes the detection of the expected roughly North-South phase surfaces of the mountain waves (de la Torre et al., 2006a). A GPS RO long term study including the whole area has not been presented up to now. This should complement previous works, as these included either a fraction of the geographical area of interest or other instruments, which cover different altitudes or spectral regions of the wave spectrum. 


\section{Data set and analysis method}

CHAMP GPS RO data have been obtained from the Jet Propulsion Laboratory (product version 1.0 of the Global Environmental and Earth Science Information System). Around 200 successful measurements were performed daily by this mission. Between 1 January 2002 and 31 December 2005 a set of 3850 cases fell into $75-35 \mathrm{~W}$ and 35-70 S, our region of study. The geographical distribution of the profiles was relatively even in this area (see Fig. 1). Although tropospheric data are available, we choose to study only the stratosphere. We do so because a particular problem associated with digital filters arises mainly around the low- and midlatitude tropopause, as the sharp change in temperature gradient sign leads to an artificial enhancement in wave activity (Schmidt et al., 2008). The vertical resolution of the temperature profiles typically ranges from $0.5 \mathrm{~km}$ in the lower troposphere to $1.4 \mathrm{~km}$ in the stratosphere (Kursinski et al., 1997), therefore only waves with vertical wavelengths greater than $2.8 \mathrm{~km}$ can be detected in our study. Several kilometers long columns may be needed for calculating the average energy (de la Torre et al., 2006c) and here we will follow this procedure. Wave activity was quantified by calculating the mean potential energy per unit mass $E_{\mathrm{p}}$ through the average relative temperature $T$ variance between altitudes $z_{1}$ and $z_{2}$ in each profile (Tsuda et al., 2000):

$E_{\mathrm{p}}=\frac{1}{z_{2}-z_{1}} \int_{z_{1}}^{z_{2}} \frac{1}{2}\left(\frac{g}{N}\right)^{2}\left(\frac{T^{\prime}}{T_{\mathrm{b}}}\right)^{2} d z$

where $g$ is the gravitational acceleration and $N$ represents the Brunt-Väisälä frequency, which may be derived from each temperature profile. The ratio of perturbation and background temperatures $\left(T^{\prime} / T_{\mathrm{b}}\right)^{2}$ was obtained as follows in each case. The $T$ profiles were low pass filtered, with a cutoff at $9 \mathrm{~km}$, obtaining $T_{\mathrm{b}}$. The filter applied is nonrecursive and a Kaiser window was used (e.g., Hamming, 1998). The filter was applied again to the difference $T-T_{\mathrm{b}}$, now with a cutoff at $3 \mathrm{~km}$, giving $T^{\prime}$ profiles, which isolate wavelengths between 3 and $9 \mathrm{~km}$. GW in this region typically belong to this range (e.g., Hocke et al., 2002). The $z_{1}-z_{2}$ vertical column for the integral was $18-27 \mathrm{~km}$ (i.e. lower stratosphere in this region).

\section{Seasonal analysis}

From energy considerations one could expect a priori that the strong tropospheric wind seasons would lead to the highest detected wave activity. In addition, the chance of finding critical zero wind levels in the troposphere (mountain waves are expected to be nearly stationary as seen from the ground) would then become low. However, the outcome is much more complicated. Larger winds imply a shift towards larger vertical wavelengths (e.g., Alexander, 1998), and although this effect leads to larger saturation amplitudes, it

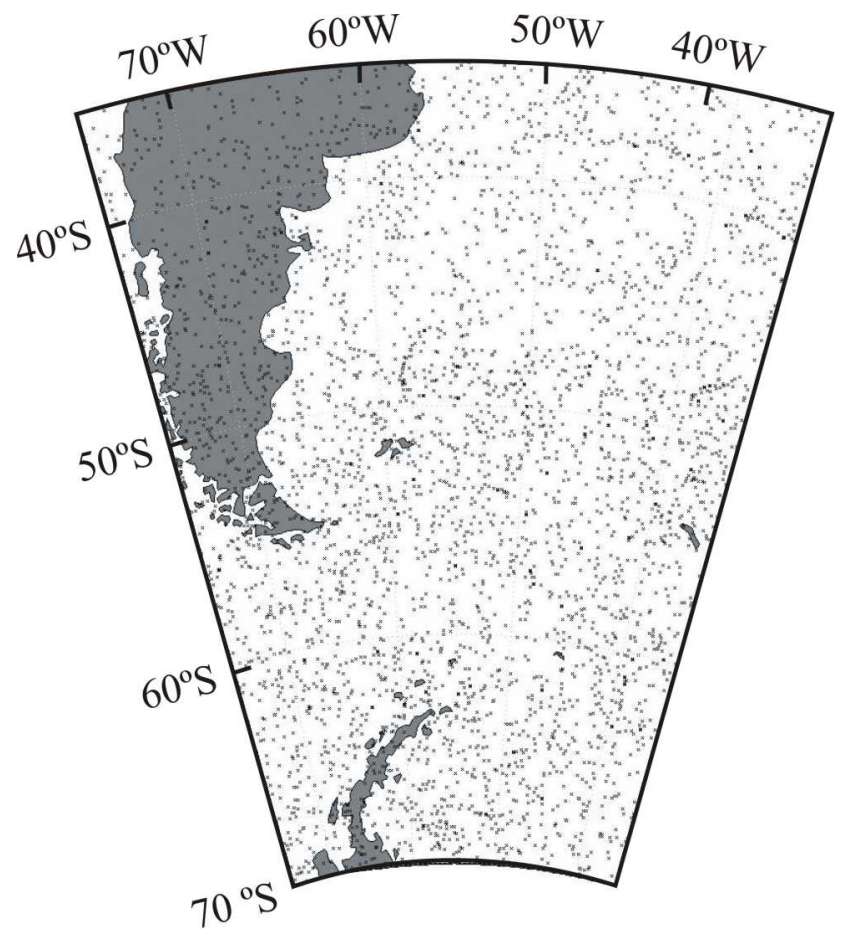

Fig. 1. The region studied and the geographical distribution of RO represented by dots.

may also take waves in or out of the observational filter of each method.

In order to examine seasonal variations of gravity wave activity detected by GPS RO, monthly means of $E_{\mathrm{p}}$ were calculated. Between a minimum of 14 and a maximum of 129 energies were averaged in each month. As shown in Fig. 2, September and October are the most intense months. This result is consistent with other works made over zones contained in our study region and/or using other methods as mentioned above (for example de la Torre et al., 2006a, analyzed GPS RO only over the region 30-40 S, 70-65 W). In the present work September 2002 has the largest average and September-October 2005 is the most extensive "high season".

We now examine the zonal background wind in the West of the region of interest (predominating eastward motion) in order to outline possible mechanisms that may explain at least a significant fraction of the seasonal behavior of potential energy. Figure 3 shows NCEP (National Center for Environmental Predicition) reanalysis data of zonal wind at longitude $75 \mathrm{~W}$ and respectively at latitudes $40 \mathrm{~S}, 50 \mathrm{~S}$ and $60 \mathrm{~S}$ between years 2002 and 2005. Although there are some particular differences at diverse latitudes, a general overview may be given. Tropospheric zonal wind is mainly eastward throughout the year. Westerlies dominate the lower stratosphere during all seasons. Above $50 \mathrm{mb}$ there are strong eastward winds during fall, winter and spring and westward 

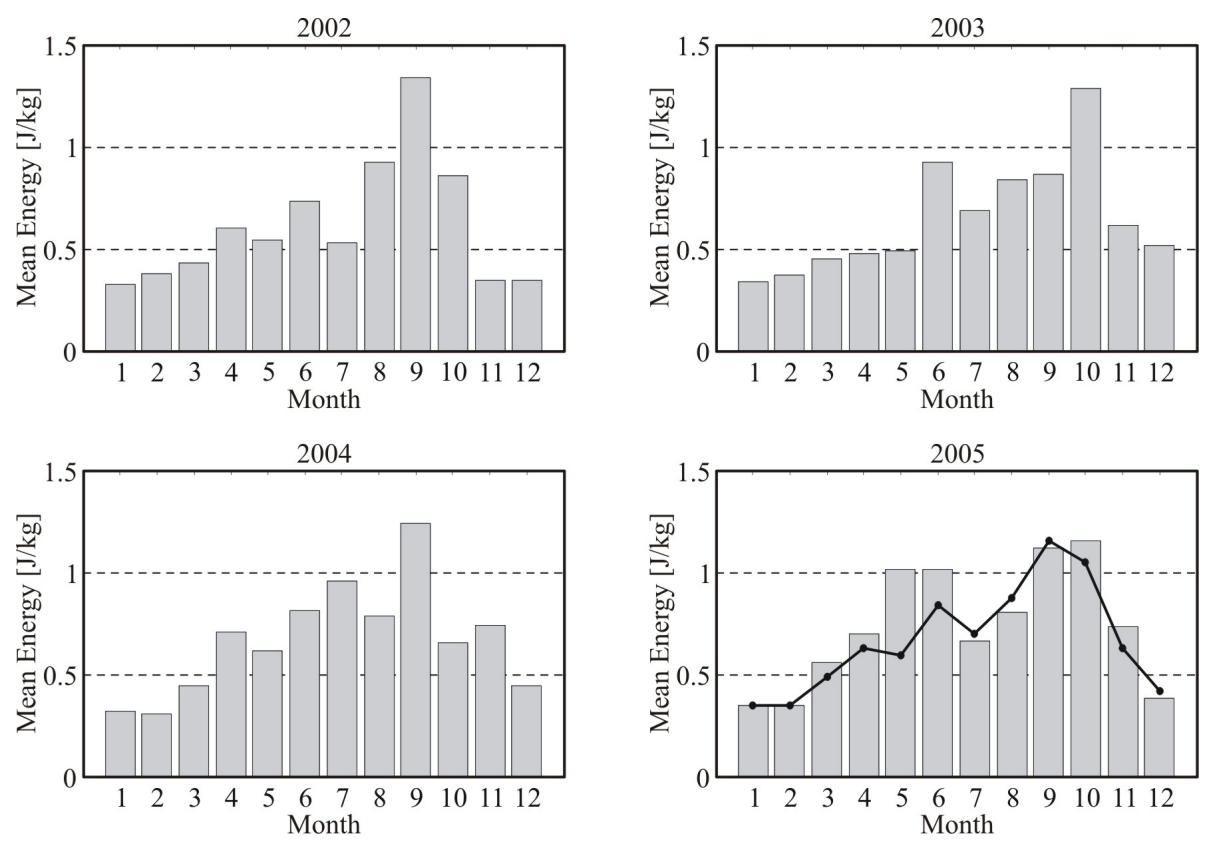

Fig. 2. Monthly means of $E_{\mathrm{p}}$ for each year of the study. The black squares in the graph for year 2005 represent the monthly averages over the four years.

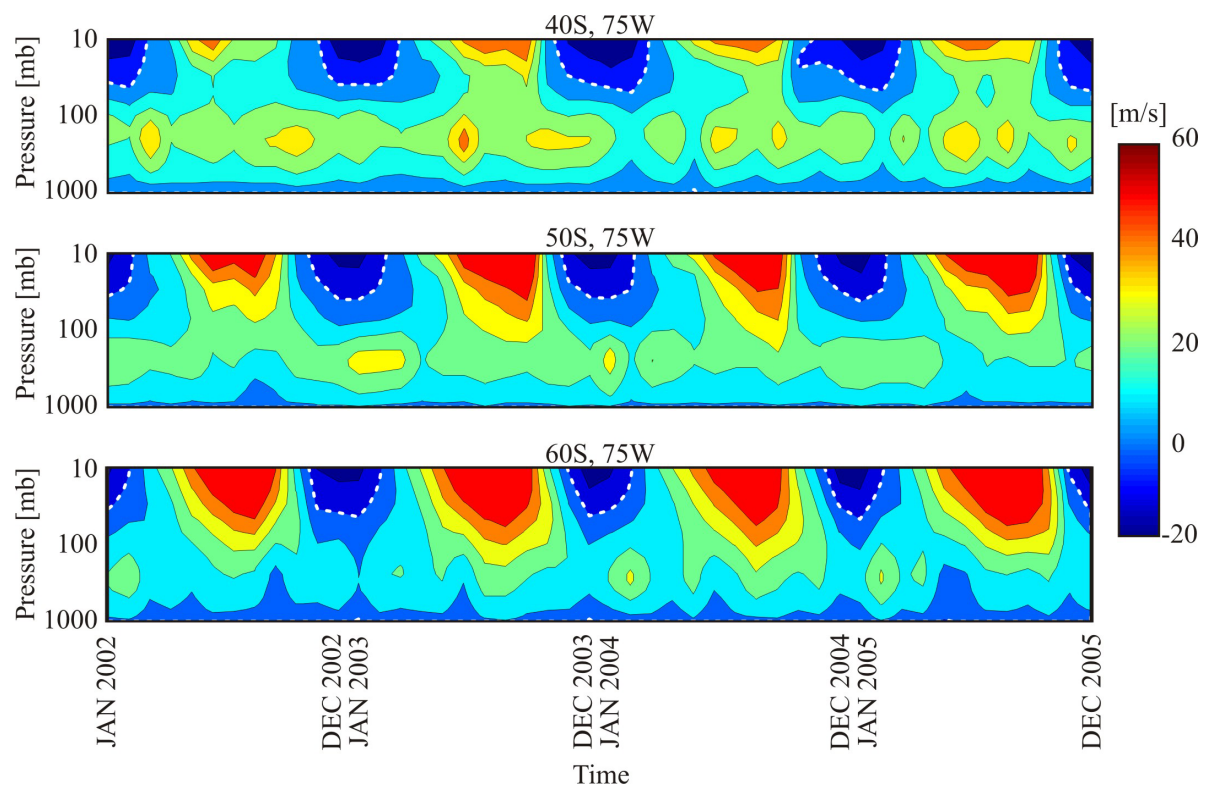

Fig. 3. NCEP reanalysis zonal wind. White dashed lines represent zero value.

winds during summer. Roughly horizontal zero zonal wind lines may be seen close to $50 \mathrm{mb}$ during summer, which thereafter become rather vertical. Then, waves with small horizontal phase velocities may be filtered out in the lower stratosphere during summer and could later reappear. This may explain why there is a first surge of observed potential energy starting around fall every year, which is partic- ularly clear in years 2003 and 2005. During late winter and early spring westerlies maximize in the stratosphere, which not only minimizes the probability of filtering out the waves, but also leads to larger saturation amplitudes as stated above, possibly leading to the observed wave activity peak during September and/or October. 


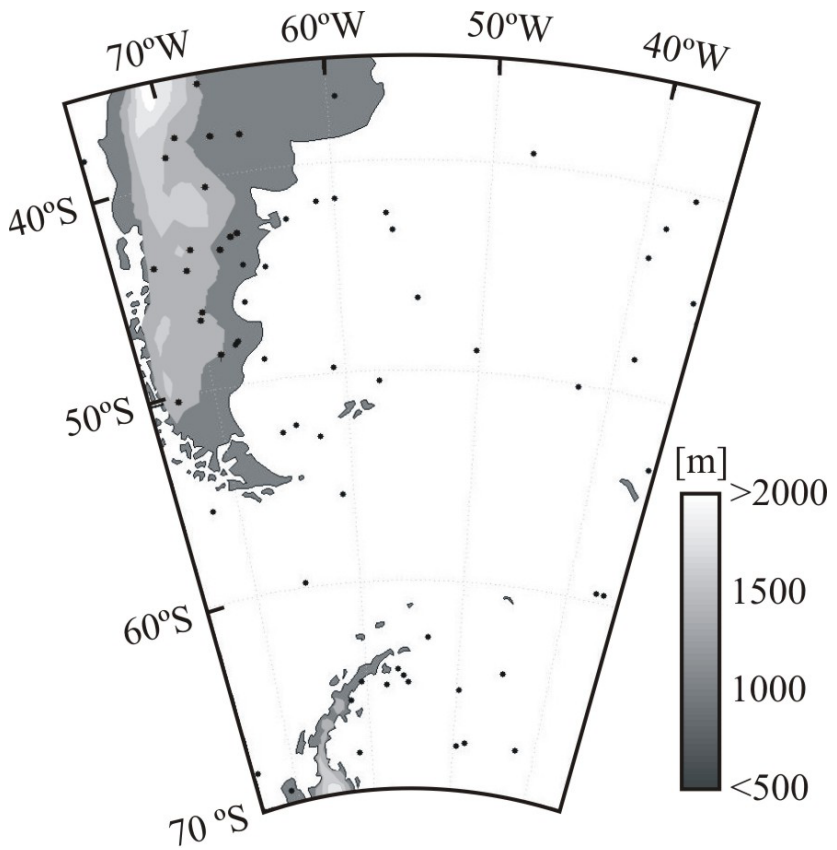

Fig. 4. Geographical distribution of events with $E_{\mathrm{p}}>4 \mathrm{~J} / \mathrm{kg}$. Topography has been included for reference.

\section{Geographical variation}

The geographical variation of $E_{\mathrm{p}}$ is examined by studying the distribution of the most energetic cases. Figure 4 shows events with $E_{\mathrm{p}}>4 \mathrm{~J} / \mathrm{kg}$. Enhancements around the Andes and the Antarctic Peninsula and their lee-sides are observed, suggesting orographic forcing of waves. Strong events are also registered over the ocean. This has also been found in other works, as mentioned above. Eckermann and Preusse (1999) detected mountain waves $400 \mathrm{~km}$ to the East of the highest Andean tops. Therefore, "long range effects" of topography should not be ruled out. Moreover, notice that only the $55 \mathrm{~S}-60 \mathrm{~S}$ latitude band has no land and that it is nearly devoid of energetic cases. Investigation of the possible source is also left here to future works. Notice however that there is a much higher probability in this study for the occurrence of strong events over land, as the ratio of their amount to continent surface is approximately five times larger than the ratio of those over ocean to the corresponding sea surface.

\section{Critical level filtering}

The GW spectrum can be significantly affected by the critical level filtering mechanism. Mountain waves have nearly zero horizontal phase velocities, so a rotation of the wind vector by $\pm 180^{\circ}$ between two heights filters all of them out (e.g., Shutts, 1998). We follow a similar approach to Baumgaert-

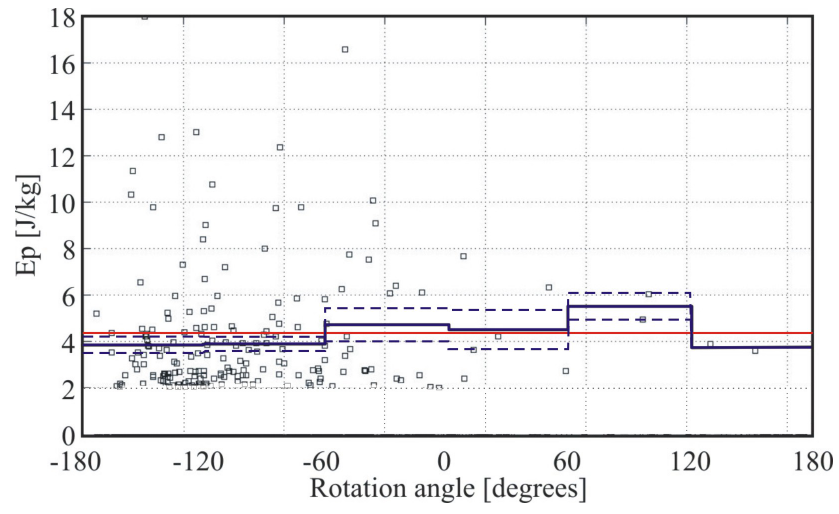

Fig. 5. $E_{\mathrm{p}}$ against the most extensive rotation angle of the wind between $1000 \mathrm{mb}$ and $50 \mathrm{mb}$ for all the studied cases. Solid lines represent the average $E_{\mathrm{p}}$ in every $60^{\circ}$ interval after removal of events below the $2 \mathrm{~J} / \mathrm{kg}$ threshold. The vertical interval corresponding to the standard deviation of the mean in each bin is represented by the dashed lines and the total average $E_{\mathrm{p}}$ (after removal of the $2 \mathrm{~J} / \mathrm{kg}$ threshold) is given by the red line.

ner and McDonald (2007) and calculate the most extensive wind rotation angle as from the 14 pressure levels between $1000 \mathrm{mb}$ and $50 \mathrm{mb}$ (the approximate lower altitude of our study interval) in the NCEP reanalysis data closest in distance and time to each occultation. The rotation angles will be considered as proxies for the amount of wave filtering. No wind rotation and $\mathrm{a} \pm 180^{\circ}$ or larger turn would, respectively, correspond to null and full filtering. In Fig. 5 we plotted potential energy against the angle for all occultations. Energy values for angle turns exceeding $+180^{\circ}\left(-180^{\circ}\right)$ have been allocated at angle turn $+180^{\circ}\left(-180^{\circ}\right)$. As there are far more data points at very negative rotation angles and the nonuniform distribution there might mislead any immediate conclusions, we developed some kind of normalized analysis according to the number of samples as explained below. We also tried to separate "noise" attributable to the observational accuracy limit from possibly true waves.

It may be appropriate to consider a threshold $E_{\mathrm{p}}$ in relation to the accuracy of RO. Those cases who fall below that limit should not be included in the following calculations. RO $T$ profiles may be considered precise to roughly $0.5 \mathrm{~K}$ (Hajj et al., 2004; Kuo et al., 2005). An integer number of sinusoidal oscillation cycles with $T^{\prime}=0.5 \mathrm{~K}$ in a typical background in the stratosphere where $T_{\mathrm{b}}=220 \mathrm{~K}$ and $N=0.02 \mathrm{~s}^{-1}$ lead in Eq. (1) to $E_{\mathrm{p}} \approx 2 \mathrm{~J} / \mathrm{kg}$. Although the effect of critical level filtering on wave activity is subtle, it is noticeable in Fig. 5 when observing the solid lines that represent the mean potential energy every $60^{\circ}$ (after removal of the $2 \mathrm{~J} / \mathrm{kg}$ threshold), as the angles close to $\pm 180^{\circ}$ have the lowest averages. The standard deviation of the mean in each bin and the total average potential energy (after removal of the $2 \mathrm{~J} / \mathrm{kg}$ threshold) have also been included. However, we must state that the 


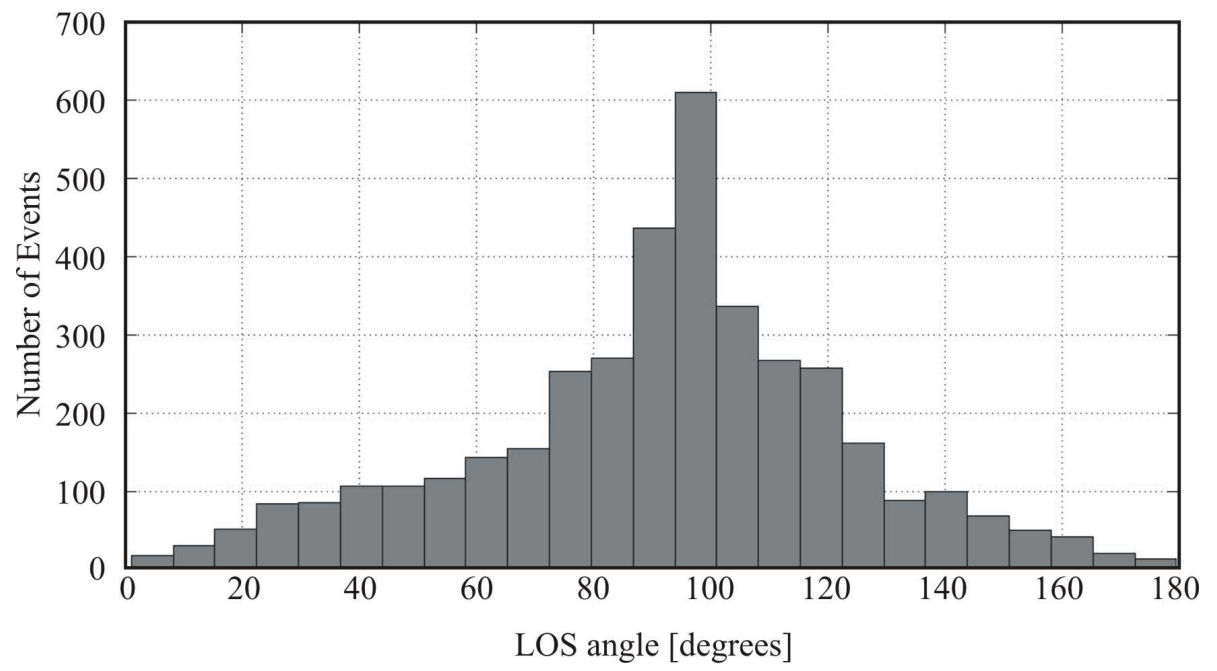

Fig. 6. LOS angle distribution for all the studied cases.

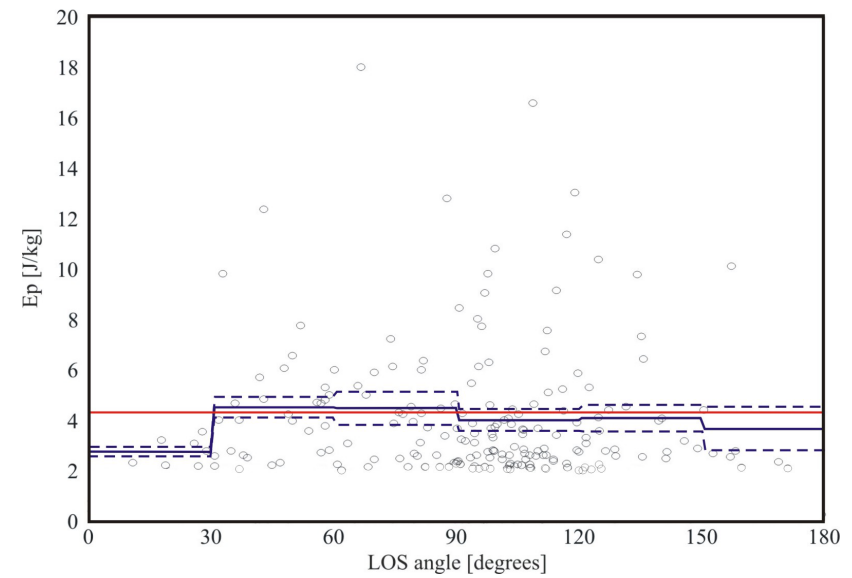

Fig. 7. $E_{\mathrm{p}}$ against LOS angle for all the studied cases. Solid lines represent the average $E_{\mathrm{p}}$ in every $30^{\circ}$ interval after removal of events below the $2 \mathrm{~J} / \mathrm{kg}$ threshold. The vertical interval corresponding to the standard deviation of the mean in each bin is represented by the dashed lines and the total average $E_{\mathrm{p}}$ (after removal of the $2 \mathrm{~J} / \mathrm{kg}$ threshold) is given by the red line.

elimination of the large amount of doubtful values below the threshold leads to a fair statistics. In particular, at positive angles very few values remain in each bin.

It should be remarked that at least four of the main mechanisms for GW generation should be considered close to Andes: deep convection, wind shear, geostrophic adjustment and topographic forcing. However, in the studies of GW observed with satellite remote sounding techniques, whenever their origin was analyzed, only the latter two types have been apparently detected (see the references in the introduction). It may happen that deep convection and wind shear GW do not fit into the observational filtering windows of these methods or that their effects are small. Emission of GW due to geostrophic adjustment (e.g., Fritts and Luo, 1992) may happen after the perturbation to equilibrium introduced in the studied region by the strong polar and subtropical jets at roughly $250 \mathrm{mb}$. Any seasonal behavior of GW arising from geostrophic adjustment should be related to the corresponding source strength variability. The intensity of both jets maximizes from autumn to winter. Therefore, the strong GW observed in this region during late winter and early spring should be mainly attributed to topographic forcing as discussed above.

\section{LOS dependence}

The circumstances under which the GPS RO technique is able to resolve gravity waves were extensively discussed by Alexander et al. (2008). The horizontal resolution of each measurement is in the worst case in the order of a few hundred kilometers along the LOS of the satellite (Kursinski et al., 1997). Mountain waves have horizontal wavelengths of tens to hundreds of kilometers (Fritts and Alexander, 2003) and therefore their detection depends on the horizontal angle between the LOS and the wavefronts. A nearly null value is optimal. In the region studied, the Andes and the Antarctic Peninsula provide a meridional obstacle for prevailing westerlies, thus preferably generating nearly North-South wavefronts (Baines, 1995). This fact would facilitate the detection of waves by GPS RO with a predominating North-South LOS orientation. In the angle distribution for all GPS RO in Fig. 6, $67 \%$ of the LOS directions fall in the range of $(90 \pm 30)$ degrees, where the angle is taken counterclockwise from the West-East direction. This prevailing viewing geometry favors the detection of the expected wavefronts in the zone. 

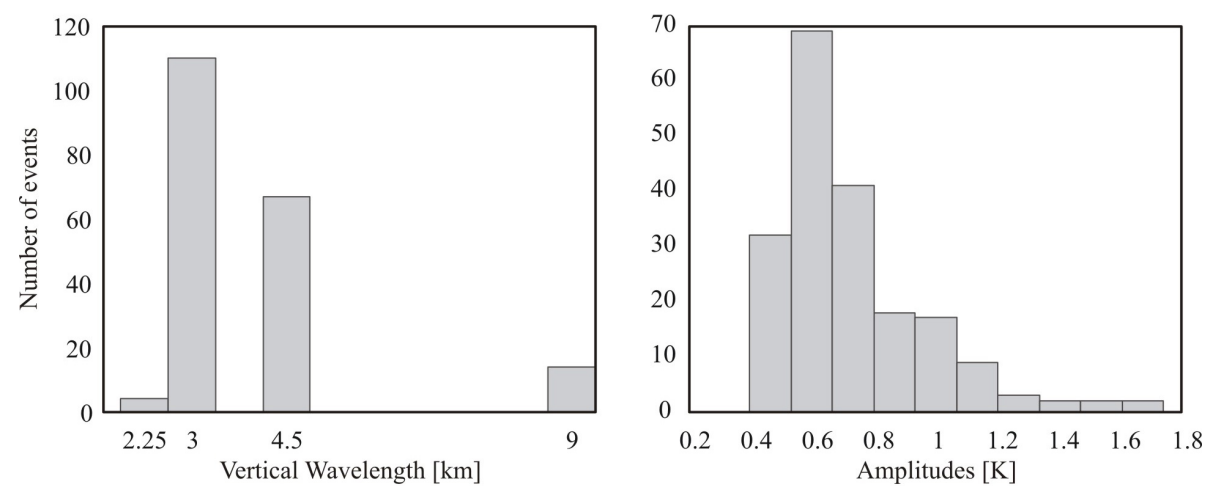

Fig. 8. Vertical wavelength and amplitude distribution for cases with $E_{\mathrm{p}}>2 \mathrm{~J} / \mathrm{kg}$.

A possible relationship between the LOS and the observed wave energy was then examined. In Fig. 7, the $E_{\mathrm{p}}$ for each RO is plotted against the LOS angle. To avoid as in Fig. 5 any inappropriate conclusions due to nonuniform distribution of data points and "noise", the average energy (after removal of values lower than $2 \mathrm{~J} / \mathrm{kg}$ ) has been included as a solid line for each $30^{\circ}$ interval. The standard deviation of the mean in each bin and the total average potential energy (after removal of the $2 \mathrm{~J} / \mathrm{kg}$ threshold) have also been included. An angle effect may be deemed. Large deviations from 90 degrees exhibit lower averages. Low activity values may be true or may be due to inappropriate observational geometry. Large energies can only be found when both conditions are met: high energy and favorable angle. Even though the mountains do not follow exactly the North-South direction and winds are not perfectly perpendicular, the largest means are found around 90 degrees (and somewhat lower angles). Although Baumgaertner and McDonald (2007) had many more cases to perform statistics in their Antarctica study, perhaps they were not able to observe this relationship because they took smaller integration columns to calculate $E_{\mathrm{p}}$ and/or because they took the wind as a proxy for wave direction, whereas it may be more appropriate to consider the wavefronts parallel to the nearly North-South alignment of the mountains (e.g., de la Torre et al., 2006a). However, we must again state that the elimination of the large amount of doubtful values below the threshold leads to a fair statistics, particularly in the first and last bin.

\section{Amplitude and wavelength distribution}

The number of observed events is large. Then, the above factors influencing GW activity (seasonality, geographical location, critical level filtering and LOS dependence) may statistically roughly balance. Therefore, a reasonable average representation of amplitude and wavelength of gravity waves generated in the studied region may be obtained. This has been performed with a Fourier analysis after removal of cases with $E_{\mathrm{p}}<2 \mathrm{~J} / \mathrm{kg}$. In order to obtain the vertical wavelengths and amplitudes we first removed any trend and mean in the temperature profiles to avoid artifacts at large wavelengths. To minimize leakage in the transformation, a Hanning truncation function was applied to the data (Brigham, 1973). The results are shown in Fig. 8. It can be seen that dominant wavelengths are found around $3 \mathrm{~km}$, whereas the shape for amplitude is very similar to what has already been equivalently observed for potential energy by Baumgaertner and McDonald (2007). It must be stated that detected and real vertical wavelengths must be distinguished for non-vertical sounding trajectories like GPS RO, whereby the discrepancy depends on the angle defined by the LOS and the wave constant phase surfaces (e.g., Alexander et al., 2008). The deviation may be significant for mountain waves, as their phase surfaces generally differ from the local horizontal plane.

\section{Conclusions}

A study performed for the years 2002-2005 for CHAMP GPS RO data in the region 75-35 W, 35-70 S shows energetic GW in the stratosphere to the East of the Andes mountains and the Antarctic Peninsula. Some cases even occur over the ocean. Typical waves have detected vertical wavelengths around $3 \mathrm{~km}$ and sub-Kelvin temperature amplitudes. Critical level filtering was found to have impact on wave energy and to imply that a large fraction of the intense activity stems from mountain waves. The most energetic cases are found when the LOS is nearly aligned with the expected wavefronts, i.e. in the N-S direction. However, caution must be exerted on these statements because their statistical significance should be considered fair, so the results must be considered preliminary. In the coming years the amount of GPS RO will continue to increase and more robust statistical answers may be found. If the results still hold, then they would show that the satellites' and regional conditions are nearly optimal for wave activity detection. Observations such as those from GPS RO would then validate the 
short vertical wavelength range of results from other satellitebased methods. Given the fact that other instruments have insinuated (they have a much lower occurrence than GPS RO) the same seasonal changes over different vertical wavelength ranges and heights in the analyzed region, we would then conclude that the observational filtering effect unlikely determines these variations.

Acknowledgements. Manuscript prepared under grants UBA X004 and CONICET PIP 5932 and ANPCYT PICT 1999. P. Alexander and A. de la Torre are members of CONICET. P. Llamedo holds a fellowship from CONICET. We acknowledge data provided by the NOAA-CIRES/Climate Diagnostics Center, Boulder (CO) from their website www.cdc.noaa.gov and the Jet Propulsion Laboratory for making available CHAMP GPS RO data for our study.

Topical Editor F. D'Andrea thanks two anonymous referees for their help in evaluating this paper.

\section{References}

Alexander, M. J.: Interpretations of observed climatological patterns in stratospheric gravity wave variance, J. Geophys. Res., 103, 8627-8640, 1998.

Alexander, M. J. and Teitelbaum, H.: Observation and analysis of a large amplitude mountain wave event over the Antarctic peninsula, J. Geophys. Res., 112, D21103, doi:10.1029/2006JD008368, 2007.

Alexander, M. J. and Barnet, C.: Using Satellite Observations to Constrain Parameterizations of Gravity Wave Effects for Global Models, J. Atmos. Sci., 64, 1652-1665, 2007.

Alexander, P., de la Torre, A., and Llamedo, P.: Interpretation of gravity wave signatures in GPS radio occultations, J. Geophys. Res., 113, D16117, doi:10.1029/2007JD009390, 2008.

Baines, P. G.: Topographic Effects in Stratified Flows, Cambridge Univ. Press, New York, 482 pp., 1995.

Baumgaertner, A. J. G. and McDonald, A. J.: A gravity wave climatology for Antarctica compiled from Challenging Minisatellite Payload/Global Positioning System (CHAMP/GPS) radio occultations, J. Geophys. Res., 112, D05103, doi:10.1029/2006JD007504, 2007.

Brigham, E. O.: The Fast Fourier Transform, Prentice-Hall, New Jersey, 246 pp., 1973.

de la Torre, A. and Alexander, P.: Gravity waves above Andesdetected from GPS radio occultation temperature profiles: Mountain forcing?, Geophys. Res. Lett., 32, L17815, doi:10.1029/2005GL022959, 2005.

de la Torre, A., Alexander, P., Llamedo, P., Menéndez, C., Schmidt, T., and Wickert, J.: Gravity waves above the Andes detected from GPS radio occultation temperature profiles: Jet mechanism?, Geophys. Res. Lett., 33, L24810, doi:10.1029/2006GL027343, 2006a.

de la Torre, A., Alexander, P., and Menéndez, C.: Are we observing mountain waves above the Andes Range from GPS occultation profiles?, in: Atmosphere and Climate: Studies by occultation methods, 243-252, Springer, Berlin, 2006b.

de la Torre, A., Schmidt, T., and Wickert, J.: A global analysis of wave potential energy in the lower stratosphere derived from 5 years of GPS radio occultation data with CHAMP, Geophys. Res. Lett., 33, L24809, doi:10.1029/2006GL027696, 2006c.
Eckermann, S. D. and Preusse, P.: Global Measurements of stratospheric mountain waves from space, Science, 286, 1534-1537, 1999.

Ern, M., Preusse, P., Alexander, M. J., and Warner, C. D.: Absolute values of gravity wave momentum flux derived from satellite data, J. Geophys. Res., 109, D20103, doi:10.1029/2004JD004752, 2004.

Fritts, D. C. and Alexander, M. J.: Gravity wave dynamics and effects in the middle atmosphere, Rev. Geophys., 41, 1003, doi:10.1029/2001RG000106, 2003.

Fritts, D. C. and Luo, F.: Gravity wave excitation by geostrophic adjustment of the jet stream. Part 1: two-dimensional forcing, J. Atmos. Sci., 49, 681-697, 1992.

Hajj, G. A., Ao, C. O., Iijima, B. A., Kuang D., Kursinski, E. R., Mannucci, A. J., Meehan, T. K., Romans, L. J., de la Torre Juarez, M., and Yunck, T. P.: CHAMP and SAC-C atmospheric occultation results and intercomparisons, J. Geophys. Res., 109, D06109, doi:10.1029/2003JD003909, 2004.

Hamming, R. W.: Digital Filters, 3rd ed., Dover Publications, Mineola, New York, 1998.

Hocke K., Tsuda, T., and de la Torre, A.: A study of stratospheric GW fluctuations and sporadic $\mathrm{E}$ at midlatitudes with focus on possible orographic effect of Andes, J. Geophys Res., 107, 4428, doi:10.1029/2001JD001330, 2002.

Jiang, J. H., Wu, D. L., and Eckermann, S. D.: Upper Atmosphere Research Satellite (UARS) MLS observation of mountain waves over the Andes, J. Geophys. Res.,107, 8273, doi:10.1029/2002JD002091, 2002a.

Jiang, J. H., Wu, D. L., Eckermann, S. D., and Ma, J.: Mountain waves in the middle atmosphere: microwave limb sounder observations and analyses, Adv. Space Res., 32, 801-806, doi:10.1016/S0273-1177(03)00402-2, 2002b.

Jiang, J. H., Eckermann, S. D., Wu, D. L., and Ma, J.: A search for mountain waves in MLS stratospheric limb radiances from the winter Northern Hemisphere: Data analysis and global mountain wave modeling, J. Geophys. Res., 109, D03107, doi:10.1029/2003JD003974, 2004.

Kuo, Y.-H., Schreiner, W. S., Wang, J., Rossiter, D. L., and Zhang, Y.: Comparison of GPS radio occultation soundings with radiosondes, Geophys. Res. Lett., 32, L05817, doi:10.1029/2004GL021443, 2005.

Kursinski, E. R., Hajj, G. A., Schofield, J. T., Linfield, R. P., and Hardy, K. R.: Observing Earths atmosphere with radio occultation measurement using the Global Positioning System, J. Geophys. Res., 102, 23429-23465, 1997.

Lange, M. and Jacobi, C.: Analysis of gravity waves from radio occultation measurements, in: First CHAMP Mission Results for Gravity, Magnetic and Atmospheric Studies, Springer, New York, 479-484, 2003.

McLandress, C., Alexander, M. J., and Wu, D. L.: Microwave Limb Sounder observations of gravity waves in the stratosphere: A climatology and interpretation, J. Geophys. Res., 105, 1194711967, 2000.

Preusse, P., Dörnbrack, A., Eckermann, S. D., Riese, M., Schaeler, B., Bacmeister, J. T., Broutman, D., and Grossmann, K. U.: Space-baed measurements of stratospheric mountain waves by CRISTA, J. Geophys. Res., 107, 8178, doi:10.1029/2001JD000699, 2002.

Shutts, G. J.: Stationary gravity-wave structure in flows with direc- 
tional wind shear, Q. J. Roy. Meteorolo. Soc., 124, 1421-1442, 1998.

Schmidt, T., Wickert, J., Marquardt, C., Beyerle, G., Reigber, C., Galas, R., and König, R.: GPS radio occultation with CHAMP: an innovative remote sensing method of the atmosphere, Adv. Space Res., 33, 1036-1040, 2004.

Schmidt, T, de la Torre, A., and Wickert, J.: Global gravity wave activity in the tropopause region from CHAMP radio occultation data, Geophys. Res. Lett., 35, L16807, doi:10.1029/2008GL034986, 2008.

Tsuda, T., Nishida, M., Rocken, C., and Ware, R. H.: A Global Morphology of Gravity Wave Activity in the Stratosphere Revealed by the GPS Occultation Data (GPS/MET), J. Geophys. Res., 105, 7257-7273, 2000.

Wickert, J., Beyerle, G., König, R., Heise, S., Grunwaldt, L., Michalak, G., Reigber, Ch., and Schmidt, T.: GPS radio occultation with CHAMP and GRACE: A first look at a new and promising satellite configuration for global atmospheric sounding, Ann. Geophys., 23, 653-658, 2005,

http://www.ann-geophys.net/23/653/2005/.
Wu, D. L. and Waters, J. W.: Satellite observations of atmospheric variances: A possible indication of gravity waves, Geophys. Res. Lett., 23, 3631-3634, 1996.

Wu, D. L. and Waters, J. W.: Observations of gravity waves with the UARS microwave limb sounder, in: Gravity Wave Processes: Their Parameterization in Global Climate Models, NATO ASI Ser., Ser. I, vol. 50, Springer-Verlag, New York, 103-120, 1997.

Wu, D. L. and Jiang, J. H.: MLS observations of atmospheric gravity waves over Antarctica, J. Geophys. Res., 107, 4773, doi:10.1029/2002JD002390, 2002.

$\mathrm{Wu}$, D. L.: Mesoscale gravity wave variances from AMSU-A radiances, Geophys. Res. Lett., 31, L12114, doi:10.1029/2004GL019562, 2004.

Wu, D. L. and Zhang, F.: A study of mesoscale gravity waves over the North Atlantic with satellite observations and a mesoscale model, J. Geophys. Res., 109, D22104, doi:10.1029/2004JD005090, 2004.

Wu, D. L., Preusse, P., Eckermann, S. D., Jiang, J. H., de la Torre Juarez, M., Coy, L., and Wang, D. Y.: Remote sounding of atmospheric gravity waves with satellite limb and nadir techniques, Adv. Space Res., 37, 2269-2277, 2006. 